\title{
Civic Engagement and Environmental Sustainability in Teaching and Learning at Higher Education Institution in South Africa
}

\section{Tererai Nhokodi - Thandiswa Nqowana - Dylan Collings - Roman Tandlich - Nikki Köhly ${ }^{*}$}

Received: August 31, 2016; received in revised form: October 11, 2016; accepted: October 14, 2016

\begin{abstract}
This article seeks to provide an outline the scope of professional teaching and learning activities and their connection to civic engagement and the achievement of environmental sustainability at Rhodes University and in Makana Local Municipality. Activities in the context of rainwater water harvesting and sanitation research are used as examples. The improved hydrogen-sulphide test kit was used as the tool for the assessment of microbial water quality between April and July 2016. An approach to the improvement in the design and modelling of the performance of ventillated improved pit latrines under laboratory conditions is also described. All activities described have been taking place in the context of undergraduate and postgraduate student research projects at Rhodes University. They have implications for teaching and learning, civic engagement and environmental sustainability. Teaching and learning of the concepts of sustainability can facilitate the development of the necessary connection between academia and the society at large. This can have a significant positive effect on societal conditions in South Africa. Further endeavours similar those described in this article should be stimulated in South and beyond.
\end{abstract}

Key words: H2s test kit, experiential learning, South Africa, Bachelor of Pharmacy, Bachelor of Science of Biotechnology

Tererai Nhokodi, Environmental Health and Biotechnology Research Group, Faculty of Pharmacy, Rhodes University, Grahamstown, South Africa; g13n2885@ campus.ru.ac.za Thandiswa Nqowana, Environmental Health and Biotechnology Research Group, Faculty of Pharmacy, Rhodes University, Grahamstown, South Africa; tnqowana@ gmail.com Dylan Collings, Environmental Health and Biotechnology Research Group, Faculty of Pharmacy, Rhodes University, Grahamstown, South Africa; dmacollings@gmail.com Roman Tandlich, Environmental Health and Biotechnology Research Group, Faculty of Pharmacy, Rhodes University, Grahamstown, South Africa; roman.tandlich@ gmail.com Nikki Köhly, Office of Enterprise Risk Management, Rhodes University, Grahamstown, South Africa; n.kohly@ru.ac.za 


\section{Acta Technologica Dubnicae \\ volume 6, 2016, issue 3}

\section{Introduction}

Civic engagement has been defined as human action which is based on the "heightened sense of responsibility" to improve of the common good and facilitate development of the society at large (Jacoby, 2012). The concept of civic engagement has played an important and implicit role in higher education in South Africa. This is best demonstrated through the three pillars of the academic project at tertiary institutions in the country, i.e. research, teaching and learning; and community engagement (Lazarus et al., 2008). Community engagement strongly encourages academic institutions to get involved in the communities they are located in (CHE, 2010). It can be said that the concept of community engagement is aimed at stimulating the development of a "working relationship" between academia and the community at large (CHE, 2010). This paradigm of human interaction and knowledge exchange has led to the development of new educational initiatives (Lazarus et al., 2010). Community engagement leads to mode 2 generation of knowledge by higher education institutions. This in turn helps document, develop and ethically exploit indigenous knowledge for the economic development of communities that are the source of such knowledge. In this context, local scientific expertise can be used to tackle pressing local challenges, e.g. in areas of service delivery in South Africa (Tandlich et al., 2014). Being drawn into the community and becoming part of it allows the academics and students from higher education institutions to nurture and develop a strong sense of civic engagement.

South Africa as a country faces many challenges which are not uncommon to developing countries. These include the following (NDP, 2012): societal challenges resulting from historical factors, current lack of skilled labour and increased need to graduate more Masters and PhDs, academic and financial challenges faced by students from underprivileged backgrounds, high unemployment rates, inadequate policy framework and slow pace of service delivery to some segments of the South African population. Under these conditions, it is often civic engagement, community engagement and the mode 2 knowledge generation mentioned above that can assist in finding solutions to societal challenges. These initiatives cannot and should not replace the need for adequate policy framework and action of all levels of government, but they can provide local solutions, as well as help develop short-term mitigation measures where necessary. When it comes to natural scientists and healthcare professionals, civic engagement in water and sanitation sectors has often led to successful interventions and proposals for long-term solutions among the affected populations (Tandlich et al., 2014).

Biotechnology at Rhodes University is taught as postgraduate degree and its core functions include the transdisciplinary engagement of biotechnology 


\section{Acta Technologica Dubnicae \\ volume 6, 2016, issue 3}

scientists/students with the community (BICC, 2016a). This is in line with the principle of community engagement. The aim is to raise awareness about the problems in the geographical location of Rhodes University, namely Makana Local Municipality. Driven by the creation of a government-funded research professorship, named South African Research Chair in Biotechnology Innovation and Engagement, the respective academic department is attempting to use the developed research solutions and tailor them to the needs of the local community (BICC, 2016a). This approach to tertiary education can in theory achieve the civic engagement among the staff and the students in the Department, as well as the local community. As it is located in a rural area of the Eastern Cape Province of South Africa, Makana Local Municipality faces many challenges in sanitation (Hoossein et al., 2016) and potable water service delivery (Luyt et al., 2011a; Tandlich et al., 2014). Thus, civic engagement of the students from the BICC should be focused into these areas of service delivery.

Training of pharmacists in South Africa is governed by regulations and the professional body of South African Pharmacy Council (SAPC, 2016a, b). Bachelor of Pharmacy is one of the professional degrees regulated by the SAPC and it is taught as a four-year degree at accredited higher education institutions in the country (SAPC, 2015). After graduation from this degree and fulfillment of additional criteria, the Bachelor of Pharmacy graduates become practising pharmacists and serve as custodians of medicines in South Africa (SAPC, 2016b, c). Service learning and community engagement are the key components of the education of Bachelor of Pharmacy candidates. These activities take place through the visits to clinics and other healthcare facilities. They facilitate interactions between patients and future pharmacists as this is at the heart of the practice of pharmacy and plays and important role in the context of public health in South Africa. These interactions prime the pharmacy students to awareness about public health challenges such as the drinking water quality and diarrhoeal diseases (Luyt et al., 2012). Civic engagement can be strengthened among the Bachelor of Pharmacy students through teaching and learning activities focused on the issues of drinking water quality. This is done at Rhodes University in the context of the final year research project which takes place over the course of one semester.

Rhodes University has a commitment to sustainability as documented by the adoption of the Rhodes University Sustainability Policy (RUSP, 2015). The policy statement in the RUSP contains a strong commitment to environmental teaching and research in areas such as waste and water management (RUSP, 2015). In the Overview part of the policy, stimulation of research and decrease of the water footprint of the university is sought (RUSP, 2015). Directive 2.2 in the Directives for the Implementation of the RUSP call for the establishment and use of alternative water sources to potable water provided by Makana Local 


\section{Acta Technologica Dubnicae \\ volume 6, 2016, issue 3}

Municipality on campus (RUSP, 2015). To achieve water sustainability and stimulate respective research and teaching activities at the Rhodes University campus, it is necessary to use strategies that also address water issues in Makana Local Municipality where the Rhodes University is located. Decreasing the water footprint of Rhodes University will require the use of rainwater and traditional water sources which have been used by the local population for decades. Relevant activities will therefore be at the interface between science, community engagement, teaching and learning, as well as civic engagement.

Rainwater tanks and harvesting systems have been installed around the Rhodes University campus and the stored water is used for potable purposes during water outages. One of the main public health threats here will originate from microbial contamination of rainwater which must therefore be assessed regularly. Use of alternative water resources is based on the indigenous knowledge from the local community. One of the non-municipal sources of potable water is a spring on at outskirts of Grahamstown, the largest urban settlement in Makana Local Municipality. In the context of their civic engagement, the fourth author and the fifth author have been involved in the monitoring of the microbial water quality of this resource since 2013. This monitoring programme was expanded in 2016 to include the monitoring of the microbial water quality in the low-income settlements located in the Eastern part of Grahamstown. At the same time, monitoring of microbial rainwater quality at Rhodes University campus was run as part of a fourth-year Bachelor of Pharmacy project. An outreach with non-scientist environmental representatives from the student residences was also initiated. Sustainability in the wider context of South Africa requires achievement of sustainable sanitation. This article seeks to provide an outline the scope of these activities in the course of professional teaching and learning activities, civic engagement and the achievement of environmental sustainability at Rhodes University and in Makana Local Municipality. Activities in the context of rainwater water harvesting and sanitation research are used as examples.

\section{Methodology}

The first author is a Bachelor of Pharmacy student who has been working on his final year project in the 2016 academic year. The second author is a Bachelor of Science Honours in Biotechnology candidate who has been working on her research thesis since May 2016. Both student projects have been focused on the monitoring of microbial quality of rainwater at Rhodes University campus and the Makana Local Municipal bulk drinking water supply. The implicit goal behind both projects has been to use sound scientific strategies to develop a water monitoring approach where the results are easily disseminated to general public who can benefit from it. Therefore, the testing procedures were to be 


\section{Acta Technologica Dubnicae \\ volume 6, 2016, issue 3}

simple and it should be possible to disseminate results to a wide range of audience with varying level of literacy.

The testing procedure fitting these criteria has been the improved hydrogensulphide test kit (designated as test kit in further text; Luyt et al., 2011a), with one exception. The sampling taps inside the houses were sterilised using baby wet wipes instead of $70 \%$. The efficiency of sterilisation was deemed comparable to the original method. The test kit has the comparable sensitivity to the standard indicator microorganism tests that are used to assess microbial water quality for human consumption (Luyt et al., 2013). The test kit results are read as a positive or negative for faecal contamination of drinking water based on a qualitative colour change (Tandlich et al., 2014). On the other hand, the test can be performed by citizen scientists and laymen after a 15 -minute training session and no laboratory equipment is required (Luyt et al., 2013).

On the scientific side, the initial task in both student projects was to ensure that the test kit results are of the exact same quality as the standard indicator microorganism tests and not just comparable. Previous studies in the Environmental Health and Biotechnology Research Group showed that the test kit was $64 \%$ as reliable as standard indicator microorganism tests when the indicator microorganism concentration is around the regulatory detection limit for drinking water quality (Luyt et al., 2011a, b; Luyt et al., 2013). Therefore, the original testing protocol of using of a single test kit per sampling site on a given sampling occasion was modified and five test kits were used per site. The test kits were prepared and the sampling was performed as described previously (Luyt et al., 2011a, b; Luyt et al., 2013; Tandlich et al., 2014). A rainwater or municipal drinking water sample is considered positive for faecal contamination, if all five test kits turn black within 72 hours of incubation after sampling. Water samples are considered negative if all five test kits are negative after 72 hours of incubation. Reliability of the test kit results using this modified protocol is 99.4 $\%$. Intermediate cases (1-4 test kits per site were positive or negative) will be discussed further in the Findings section below.

In the context of student projects, a combined selection of sampling sites was followed. The first author sampled three rainwater tanks at the Rhodes University campus. The tanks were located in the various parts of campus. One tank was located in a public area outside an academic department and it is used as a source of water for drinking by the staff of this department. The site was chosen due to ease of access, but also due to the concerns of the academic department's staff about the microbial water quality of the sampled rainwater. This sampling site is designated as Department in the further text. The second sampling site was a rainwater storage tank located outside a student residence in a public area at Rhodes University campus. This tank serves as a source of 


\section{Acta Technologica Dubnicae \\ volume 6, 2016, issue 3}

potable water for students and residence staff during a municipal drinking water outage. This tank will be designated as Residence in further text. The last rainwater tank was located at a Bed and Breakfast facility on Rhodes University campus. The purpose of the tank as a drinking water source and its selection as a sampling site were based on the same reasoning as in the case of the student residence. This tank is designated as BNB in further text.

Sampling took place between April and July 2016; and a total of six separate samples were taken at each site. Permission for sampling of all rainwater tanks was obtained from the relevant Rhodes University officials (Infrastructure Division) and the results of the analyses were provided to them. All sampled rainwater tanks were located in public areas where no one can have an expectation of privacy. Finally, no data on human subjects was collected during any part of the current study and no interviews with tanks users were run. Therefore, no ethical approval for the sampling or any part of the study was required. Selection of sampling sites was based on the authors' expertise (first, fourth and fifth author) and would provide the most relevant information to the university authorities on the use of alternative water sources, as it intersects the entire spectrum of water consumers on campus. Collecting information on microbial rainwater quality will facilitate the achievement of the goals of the RUSP in the area of Rhodes University's water resource management and water footprint (see above).

The second author sampled municipal drinking water taps between May and August 2016; and a total of three separate samples were taken at each site. The first municipal drinking water source was located inside the second author's private house (designated as East 1 in further text), while the second one was a communal tap located inside a municipal settlement in the Eastern part of Grahamstown, close to where the second author resides (designated as East 2 in further text). Third sampling site in the Eastern part of Grahamstown was a fire hydrant supply of potable water/water tanker which was provided to meet the domestic water consumption of the residents during a municipal drinking water outage or during the low pressure in the municipal drinking water supply grid. The third site was only sampled once, as there was only one municipal drinking water outages during the study (designated as Water tanker). The second author chose all three sampling sites based on her scientific understanding of public health and water microbiology. She also chose the sites based her knowledge and understanding of the water supply in the area and her concerns about possible implications of inferior microbial drinking water in her community. The second author sampled all the sites herself. These sampling sites were located inside the second author's house or in a public area where no can have an expectation of privacy. At the same time, the second author's initiatives demonstrate a combination of scientific expertise and civic engagement. 


\section{Acta Technologica Dubnicae \\ volume 6, 2016, issue 3}

The choice of the sites was also based on the second author's "heightened sense of responsibility" to improve of the common good through providing the information about public health implications of municipal drinking water quality. Her activities thus constitute civic engagement (Jacoby, 2012). Based on these facts, no ethical approval for the sampling was required as no personal information about any human subjects was collected in any fashion whatsoever. Significance of civic engagement as a direct and indirect outcome of both abovementioned student projects in Makana Local Municipality lies in the fact that water quality problems are common and water outages occur at least once a year (Luyt et al., 2011a). This was the case again in 2016 when a water outage throughout the entire supply grid which took place and could potentially affect the running of the National Arts Festival in Grahamstown (NAF, 2016).

This event is a major source of revenue for Grahamstown, Makana Local Municipality and Rhodes University and it took place from 30th June until 10th July 2016 (NAF, 2106). On 29th June 2016, the municipal drinking water supply was interrupted, potentially posing logistical problems for the organisers of the 2016 National Arts Festival. The authors, driven by the fourth author, conducted an opportunistic sampling to ascertain microbial water quality in Grahamstown and at Rhodes University campus. This took place at various times after the municipal water supply had been re-established following the outage. Two samples were taken at Rhodes University Campus, two in a private house in Grahamstown, one in commercial premises in Grahamstown. Results were communicated to the Rhodes University official, house and business owners. All relevant ethical considerations were adhered to and no personal data or involvement of the human subjects in the study was conducted. The civic engagement of the authors was again the driving force behind this effort.

Besides drinking water supply, sanitation is another major challenge in Makana Local Municipality and in South Africa at large (Hoossein et al., 2014; 2016). The third author has been working on his Bachelor of Science Honours degree in Biotechnology and his research work commenced in May 2016. The topic of the project was the use of fly ash as an additive for the ventillated improved pit latrines (VIPs). These systems have been designated as the minimum standard of improved sanitation by the South African government (Hoossein et al., 2014). Advantages of VIPs include that they can be built in decentralised settings and in areas of uncontrolled/unregulated urbanisation, i.e. in informal urban settlements. However, the problems arise when the pits become full and their emptying is not done due to skills and financial shortages (Still \& Foxon, 2012). Traditional methods of waste management of the faecal sludge from VIP pits requires removal by vacuum tankers and/or the in-situ treatment via anaerobic digestion is assumed/stimulated (Still \& Foxon, 2012). The problem is that stabilisation of faecal sludge through anaerobic digestion proceeds very slowly, 


\section{Acta Technologica Dubnicae \\ volume 6, 2016, issue 3}

or not at all, while emptying technologies available in developing countries also suffer from limitations (Thye et al., 2011). Therefore, a novel approach to in-situ treatment and management of such faecal sludge is required. The third author's Honours project was aimed at attempting the use of alkaline hydrolysis via the addition of fly ash to achieve the VIP faecal sludge stabilisation and volume reduction.

Justification for this approach is based on preliminary experiments in the Environmental Health and Biotechnology Research Group which indicate that addition of fly ash can raise the $\mathrm{pH}$ of the VIP faecal sludge to 13.0 or above (data not shown). This should facilitate the alkaline hydrolysis of polymers which are normally found in faecal sludge, e.g. cellulose from toilet paper and proteins from faeces and greywater (van Loon \& Glass, 1997). To test practical feasibility of this approach, the topic of the Honours project of the third author became the "Optimisation of the fly of ash as a pit additive in VIPs". The first task of the project was to optimise/build a miniature version of the VIP pit in the laboratory. The small-scale model would provide a possibility to optimise the dosage rate of fly ash, investigate the structural integrity of the VIP vault and ascertain the factors controlling the stability of VIPs under field conditions.

The third author was empowered to take ownership of the project and to use his skills from the bee-hive making industry to achieve the goals of the project. Completing the project goals should facilitate the improved management of faecal sludge in informal/peri-urban settlements in South Africa. This way Rhodes University academics and postgraduate students will help the community deal with pressing public health challenges which originate from the improper management of the VIP faecal sludge (Still \& Foxon, 2012). All these activities should contribute to the achievement of the goals of the RUSP through the development of research and teaching of environmental sustainability. At the same time, if the findings of these Honours projects are implemented in sanitation provision in South Africa, the civic engagement of the biotechnology Honours students could be strengthened. 


\section{Acta Technologica Dubnicae \\ volume 6, 2016, issue 3}

\section{Findings}

Results from the water testing are shown in Table 1.

Table 1

Results from water testing

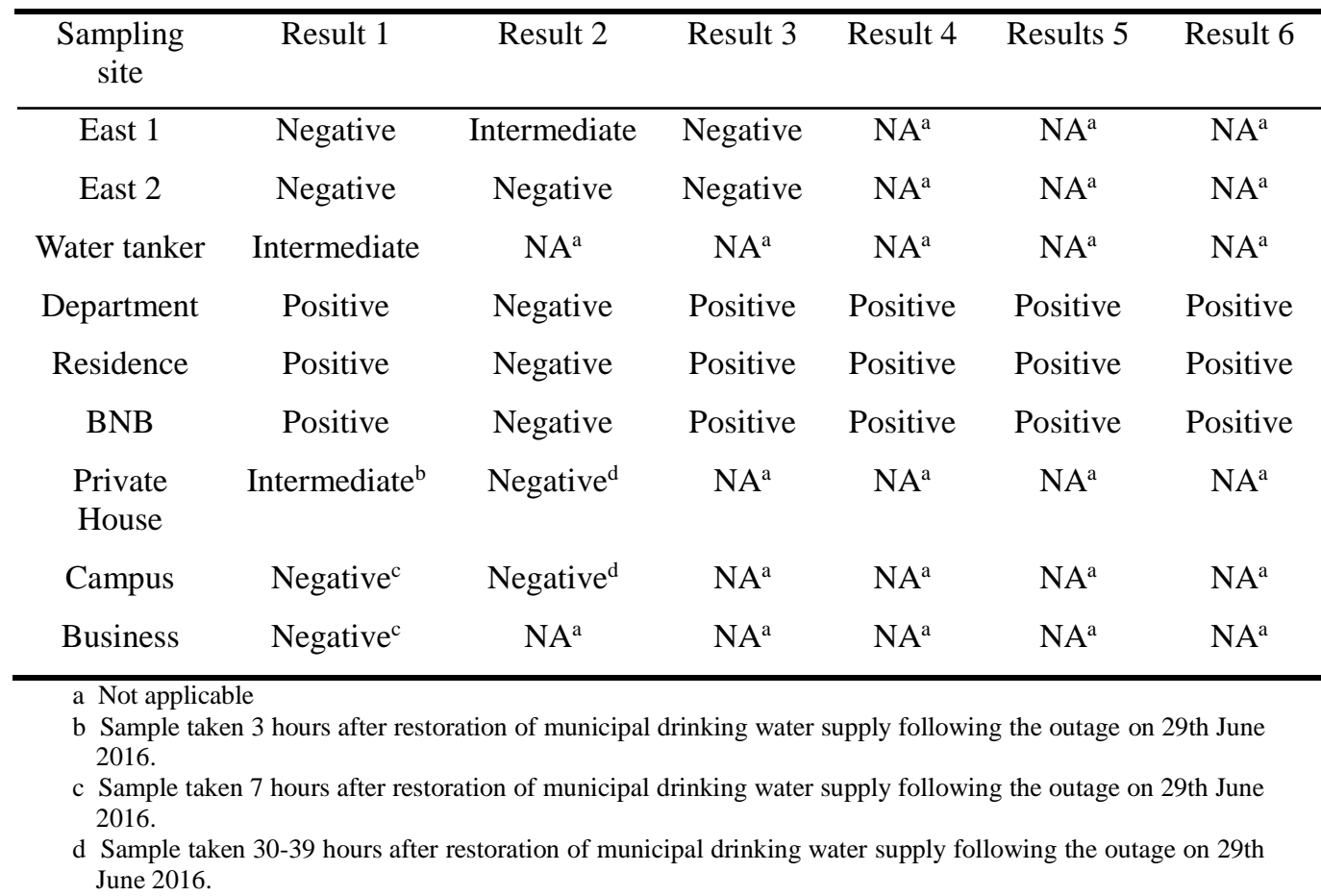

All field blanks, i.e. boiled or autoclaved water sample which was processed in the same way as field samples, were negative. Therefore, the sampling procedure did not have any effect on the test kit results obtained. A total of 30 samples were taken during the water sampling part of this study. Fifteen samples or $50 \%$ of all samples were positive for faecal contamination and all of these samples were taken from rainwater tanks at Rhodes University campus. Three samples or $10 \%$ were classified as intermediate, i.e. between 1 and 4 test kits turned positive after 72 hours of incubation. The remaining $40 \%$ of all samples taken were negative for faecal contamination. Out of the 11 samples from municipal drinking water supply or emergency water supply, 8 samples or $72 \%$ were negative for faecal contamination. This percentage is lower than the drinking water percentage of compliance, i.e. negative microbial quality results, reported by the Makana Local Municipality website (Makana, 2016). Therefore, the study results seem to indicate that the potable water supplied by Makana 


\section{Acta Technologica Dubnicae \\ volume 6, 2016, issue 3}

Local Municipality is likely not meeting the regulatory requirements for microbial water quality.

To address this, a two-fold strategy has been adopted and will be used by the authors going forward. An information brochure is being designed by the authors in English and isiXhosa (both the main languages spoken in the area of Makana Local Municipality) and these will be distributed to the population. An awareness campaign about possible problems with microbial water quality will be run in the community, pending ethical approval from the respective institutional committee. A website has been designed by the Environmental Health and Biotechnology Research Group where results will be presented to the public. Social network platforms will also be used for this purpose. A "trafficlight" system will be applied, where the results will be presented as negative (green light/colour) being reported as no danger is present, as intermediate (orange light/colour) being reported potential danger is present and mitigation measured (such as boiling of water might be required by the population before municipal drinking water consumption); and finally as positive (red light/colour) being reported definite danger to public health exists if the municipal drinking water is consumed. These messages can be sent via smartphones or disseminated in other avenues to be explored during future research.

The second part of strategy will include the expansion of the rainwater testing initiatives from this article to the entire Rhodes University campus. This has been running in part for two years now, but the new test kit protocol with five kits per site has only recently been adopted. The results from the first author's student project indicates that this activity of critical importance to public health on campus. This is the case as microbial quality of emergency water supply and alternative water supply which can be used to achieve the goals of RUSP is problematic. Civic engagement of the authors, especially the fifth author, has driven the testing programme at Rhodes University campus in collaboration with student representatives from the various residences on campus. These are elected as environmental representatives of the particular residence. The results are evaluated in collaboration with the fourth and fifth author and any treatment required is executed by the Infrastructure Division of Rhodes University.

The third author started researching building methods which can be used to build a scaled-down version of a VIP pit/vault. Over a course of this activity and while taking ownership of his Honours project, the third author designed a mould that is depicted in Figure 1. The mould allows for the preparation and testing of various concrete mixtures and setting of a complete VIP. The outer jacket of the mould can be opened on one side which allows for the removal of the final model VIP after setting (see Figure 1a). The inner prism is pushed into the mould to give shape and allow for the setting of the desired shape of the VIP pit 


\section{Acta Technologica Dubnicae \\ volume 6, 2016, issue 3}

or vault (see Figure 1b). This demonstrated in more detail in Figure 1c) where the tested concrete mixture has been placed into the mould. Finally, the VIP pit/vault is shown in Figure 1d). The third author used the mould to design a functional and scaled-down VIP pit after various attempts as shown in Figure 2. Removal of the model VIP pit/vault was a problem as the scaled-down VIP pit collapsed upon removal. This was the case even when the inner prism of the mould was greased with wax (see Figure 2 a). However, the attempt was successful with lining the inner prism with plastic rubbish bag (see Figure $2 b$ ).

The design of the mould is very simple, or even basic. However, the simplicity is what it makes an ideal research and teaching tool. The system allows for the testing of various concrete and/or cement mixtures to see which one can be used to set properly and form a stable VIP under field conditions. On the other hand, the skills shortage and inferior construction of VIPs have been an ongoing problem in South Africa (Hoossein et al., 2014; 2016). The mould devised by the third author provides a simple tool to demonstrate and educate sanitation and construction workers from local municipalities about proper constructions about the VIP pit/vaults. The mould can easily be reproduced from local materials anywhere around South Africa and used to test available construction materials for their suitability in building of the VIPs. At the same time, the mould can easily be modified to use for other purposes, e.g. building of rainwater tank models in rural areas. Model VIPs which are produced in the moulds devised in the third author's Honours project can also provide the chance for detailed study of the mechanism of faecal sludge stabilisation in the VIP pit/vault.

a)

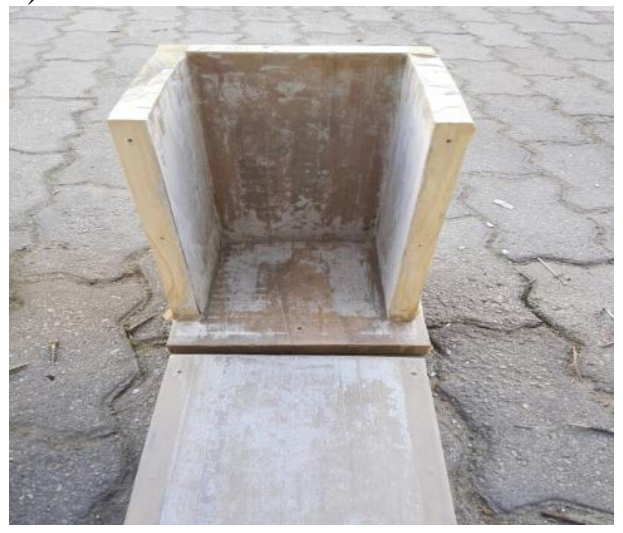

b)

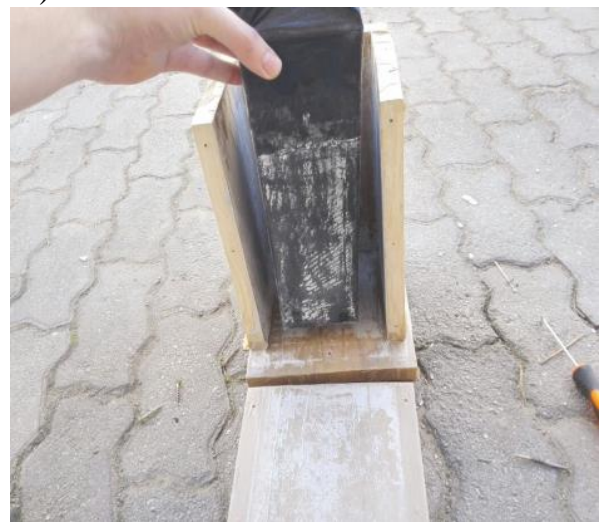


c)

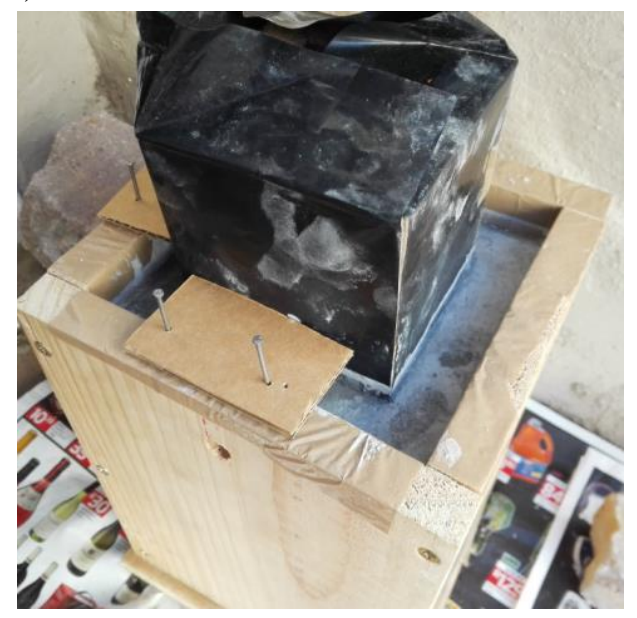

d)

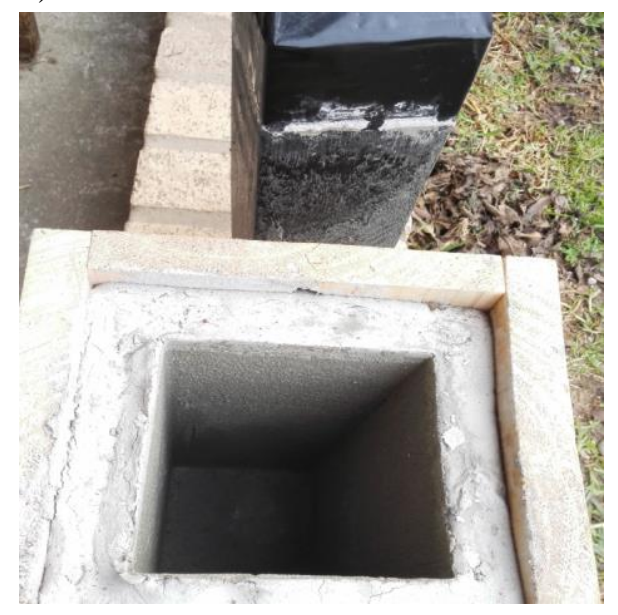

Figure 1. The mould for building the scaled-down model of the VIP. Outer jacket of the mould without any cement/concrete mixture (a), complete mould with the outer jacket and the inner prism which is lined with a plastic rubbish bag (b), complete mould with a concrete mixture (c) and the mould before the removal of the final scaled-down version of the VIP (from the outer jacket; d).

The structural stability of the pit/vault can be examined visually, or the pit/vault can be dissembled and used in the electron microscopy examination of its structural integrity. This is of particular use if the pits/vaults will be exposed to highly alkaline $\mathrm{pH}$, such as those which can be expected in the VIP pits/vaults upon addition of fly ash.

Teaching and learning of a complex discipline, such as that of environmental sustainability, is not an easy task (Kerekes \& Wetzker, 2013). The fourth author provided guidance and supervision on the overall scientific nature and execution of all student projects described above. However, the student authors were allowed to proceed and come up with details of the project themselves. Such empowerments is likely to lead to students taking ownership of their projects. It will also stimulate sustainability teaching and learning; and research at Rhodes University. As a result, such activities and those similar to them can lead to the fulfillment of the aims of the RUSP. This is especially the case as the students have gained skills they can use in training of municipal environmental health practitioners, sanitation and construction workers could improve the reliability of the VIP and the significance of microbial water quality. This can help decrease the extent of environmental contamination due to leaching of the VIP pit/vault contents into the groundwater, as well as help raise awareness and 
improve citizen understanding of microbial quality of municipal drinking water and rainwater.

a)

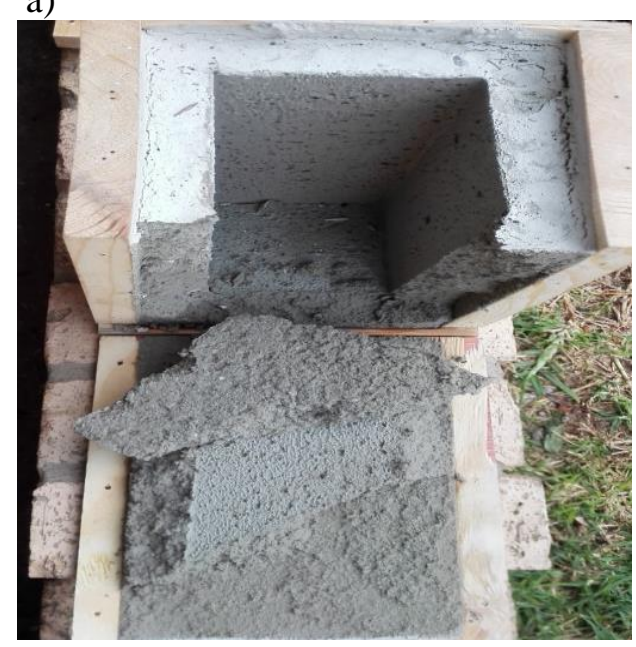

b)

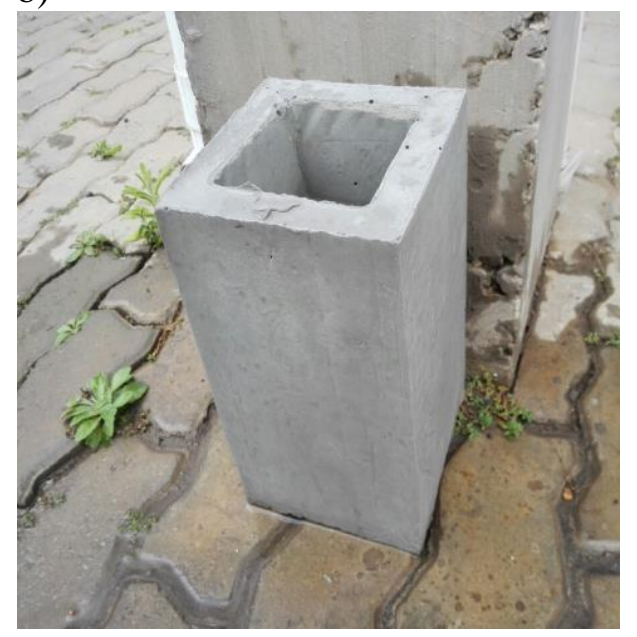

Figure 2. The mould for building the scaled-down model of the VIP. Failed attempt using wax as a releasing agent (a); Successful attempt of the model VIP vault (b).

Pharmacy synthesises the knowledge from chemistry, biology, biochemistry, pharmacology and social sciences, among others (RUPDS, 2015). Biotechnology is based on the foundation of biochemistry, microbiology, molecular biology and knowledge from other fields (BICC, 2016b). Therefore, both Pharmacy and Biotechnology are inter-disciplinary fields, i.e. the students studying them must synthesise knowledge from various fields of knowledge. Topics of all student projects described in this article required the students to synthesise knowledge to achieve the project goals. Therefore, the projects are based on the same skills as the degree that the first, second and third author have been studying towards. The project topics build on the foundation of the tertiary education that the students have received thus far. The added value comes from the real-life dimension of the knowledge/the study activities described in this article and all related activities that the first, second and third author have been exposed to. Using the same fundamental principle in the project, as the students were required to use during their undergraduate studies, is likely to facilitate the linking the students' undergraduate and postgraduate education and gained knowledge to the real-life problems that South Africa faces as a country. 


\section{Acta Technologica Dubnicae \\ volume 6, 2016, issue 3}

The fourth and the fifth authors have experience with civic engagement through their prior activities in the context of the water monitoring and water research (Tandlich et al., 2015), as well as sanitation research in South Africa (e.g. Whittington-Jones et al., 2011). Therefore, the interactions between the student co-authors and the fourth and fifth authors can help develop a sense of empowerment among the students taking part in practical project work. The sense of empowerment is mainly based on the students' gaining "meaning/selfefficacy" and "self-determination" (Nicolaidis \& Koutroumpezi, 2008). Such empowerment can in turn be a positive motivator in the students to achieve develop and implement solutions to the studied problems (Reilly et al., 2008). These solutions are extremely important in the local context of the teaching and learning activities described in this article. This will be of critical importance in the undergraduate and postgraduate research projects in South Africa. It helps equip the young professionals in the country to tackle challenges from complex and interdisciplinary phenomena such as climate change.

\section{Conclusions}

The initiatives described in this article point to the synthesis of scientific expertise, postgraduate teaching and civic engagement. Teaching and learning of the concepts of sustainability can facilitate the development of the necessary connection between academia and the society at large. It also empowers students to take charge of their own learning, achieve maximum benefits out if it and make them aware of the challenges facing South Africa in the water and sanitation sectors. This can have a significantly positive effect on societal conditions in South Africa. Further endeavours similar those described in this article should be stimulated in South and beyond.

\section{Acknowledgements:}

The authors would like to thank the Biotechnology Innovation and Communication Centre at Rhodes University for funding the study in part.

\section{References}

Council on Higher Education of South Africa (CHE, 2010). Community Engagement in South African Higher Education. Kagisano report no. 6. Retrieved from http://www.che.ac.za/sites/default/files/publications/ Kagisano_No_6_January2010.pdf

Hoossein, S., Tandlich, R., Whittington-Jones, K., Laubscher, R. K., Madikizela, P., \& Zuma, B. M. (2016). Disaster Management policy options to address the sanitation challenges in South Africa. Journal of Environmental Health, 78(7), E1-E7. 


\section{Acta Technologica Dubnicae \\ volume 6, 2016, issue 3}

Hoossein, S., Whittington-Jones, K., \& Tandlich, R. (2014). Sanitation policy and prevention of environmental contamination in South Africa. Environmental Engineering and Management Journal, 13(6), 1335-1340.

Kerekes, S., \& Wetzker, K. (2013). How to teach a complex discipline in a changing learning environment: the example of sustainability. Journal of Environmental Sustainability, 3(3), Article 2.

Jacoby, B. (2012). Civic engagement in higher education. Retrieved from http://sla.fgu.edu.tw/attachments/article/124/FINAL\%20FINAL\%20CEIHE \%20-\%20NTNU\%2012-8-14.pdf

Lazarus, J., Erasmus, M., Hendricks, D., Nduna, J., \& Slamat, J. (2008). Embedding community engagement in South African higher education. Education, Citizenship and Social Justice, 3(1), 57-83.

Luyt, C. D., Muller, W. J., \& Tandlich, R. (2013). Calibration of bifidobacterial indicators for microbial water quality monitoring in South Africa. Peerreviewed proceedings form the 13th GeoConference SGEM from 16th until 22nd June, 2013: Water Resources. Forest, Marine and Ocean Ecosystems (pp. 47-54). Albena, Bulgaria.

Luyt, C. D., Tandlich, R., Muller, W. J., \& Wilhelmi, B. S. (2012). Microbial monitoring of surface water in South Africa. International Journal of Environmental Research and Public Health, 9(8), 2669-2693.

Luyt, C. D., Muller, W. J., \& Tandlich, R. (2011a). Low-cost tools for microbial quality assessment of drinking water in South Africa. HealthMed, 5(6), Supplement 1, 1868-1877.

Luyt, C. D., Muller, W. J., \& Tandlich, R. (2011b). Factors influencing the results of microbial surface water testing in South Africa. International Journal of Medical Microbiology, 301(S1), 28-29.

Makana Local Municipality (2016). Water and wastewater quality analysis results for the month of May 2016. Retrieved from www.makana. gov.za/wp-content/uploads/2014/07/Water-Quality-Compliance -SummaryMay-2016.pdf

National Arts Festival (NAF, 2016). Retrieved from https://www.nationalartsfestival.co.za/ 2016-festival/

Nicolaidis, C. S., \& Koutroumpezi, E. (2008). Empowerment in tertiary education: a strategic source of learning advantage: The case of Greek universities. Industry and Higher Education, 22(3), 183-188(6).

Reilly, S., Petrillo, H., \& Demchik, M. (2008). Environmental Education's Role in Sustainable Development: Three Case Studies from India, South Africa and the United States. Retrieved from www.uwsp.edu/forestry/ StuJournals/Documents/IRM/Reilly.pdf

Rhodes University Academic Departments (BICC, 2016a). Biotechnology Innovation Centre. Retrieved from https://www.ru.ac.za/media/ rhodesuniversity/ 


\section{Acta Technologica Dubnicae \\ volume 6, 2016, issue 3}

content/registrar/documents/prospectus/department\%20biotech\%20innovati on\%20centre.pdf

Rhodes University Biotechnology Innovation Centre (BICC, 2016b). Courses/Applying. Retrieved from http://www.ru.ac.za/biotech/ coursesapplying/

Rhodes University Pharmacy Degree Structure (RUPDS, 2015). Admission Gateway. Retrieved from https://www.ru.ac.za/admissiongateway/ application/curriculumselection/pharmacy/

Rhodes University Sustainability Policy (RUSP, 2015). Rhodes University Sustainability Policy. Retrieved from https://www.ru.ac.za/environment/ policy/about/

South African Government (NDP, 2012). National Development Plan 2030 Our future - make it work (executive summary). Retrieved from http://www.gov.za/sites/www.gov.za/files/Executive\%20Summary-NDP\% 202030\%20-\%20Our\%20future\%20-\%20make\%20it\%20work.pdf

South African Pharmacy Council (2016a). Education. Retrieved from http://www.pharmcouncil.co.za/B_Edu_Training.asp

South African Pharmacy Council (SAPC, 2015). List of approved providers and courses. Retrieved from http://pharmaciae.org.za/list-of-approvedproviders-and-courses-3/

South African Pharmacy Council (2016b). Pharmacy Act 53 of 1974 (consolidated). Retrieved from http://www.mm3admin.co.za/documents/ docmanager/0C43CA52-121E-4F58-B8F6-81F656F2FD17/00010723.pdf

Still, D., \& Foxon, K. (2012). Tackling the challenges of full pit latrines Volume 2: How fast do pit toilets fill up? A scientific understanding of sludge build up and accumulation in pit latrines, Report no. WRC Report No. 1745/2/12. Pretoria, South Africa: Water Research Commission of South Africa.

Tandlich, R., Luyt, C. D., Irwin, B., Thinyane, H., \& Köhly, N. (2015). Nongovernmental information sources about microbial drinking water quality in South Africa. Peer-reviewed conference proceedings from the 15th SGEM GeoConference on Water Resources from 18th until 24th June, 2015: Forest, Marine and Ocean Ecosystems, Volume 2: Ecology, economics, education and legislation conference proceedings - ecology and environmental protection environmental legislation, multilateral relations and funding opportunities (pp. 761-768). Albena, Bulgaria: STEF92 Technology.

Tandlich, R., Luyt, C. D., \& Ngqwala, N. P. (2014). A community-based rainwater monitoring and treatment programme in Grahamstown, South Africa. Journal of Hydrocarbons, Mines and Environmental Research, 5(1), 46-51. 


\section{Acta Technologica Dubnicae \\ volume 6, 2016, issue 3}

Thye, Y., Templeton, M. R., \& Ali, M. (2011). A critical review of technologies for pit latrine emptying in developing countries. Critical Reviews in Environmental Science and Technology, 41, 1793-1819.

Van Loon, L. R., \& Glass, J. R. (1997). Review of kinetics of alkaline hydrolysis of cellulose in view of its relevance for safety assessment of radioactive waste repositories. Journal of Environmental Polymer Degradation, 5(2), 97-109.

Whittington-Jones, K., Tandlich, R., Zuma B. M., Hoossein, S., \& Villet, M. H. (2011). Performance of the pilot-scale mulch tower system in treatment of greywater from a low-cost housing development in the Buffalo City, South Africa. International Water Technology Journal, 1(2), Paper 7. 